\title{
Identification and Verification of the Main Differentially Expressed Proteins in Gastric Cancer via iTRAQ Combined with Liquid Chromatography-Mass Spectrometry
}

\author{
Zhihua Gao $\mathbb{D}^{1},{ }^{1}$ Jiabao Wang, ${ }^{2}$ Yuru Bai, ${ }^{3}$ Jun Bao, ${ }^{4}$ and Erqing Dai ${ }^{5}$ \\ ${ }^{1}$ Shenzhen Traditional Chinese Medicine Hospital, Shenzhen Guangdong 518000, China \\ ${ }^{2}$ Tianjin University of Traditional Chinese Medicine, Tianjin 301617, China \\ ${ }^{3}$ Department of Oncology, Nanjing Jiangning Hospital of Traditional Chinese Medicine, Nanjing Jiangsu 211100, China \\ ${ }^{4}$ Nanyang Traditional Chinese Medicine Hospital, Nanyang Henan 473000, China \\ ${ }^{5}$ Department of Military Medical and Health Care, Characteristic Medical Center of Chinese People's Armed Police Forces, \\ Tianjin 300162, China
}

Correspondence should be addressed to Zhihua Gao; gaozhihua1987@126.com and Erqing Dai; erqingdai@163.com

Received 21 July 2019; Accepted 6 November 2019; Published 1 December 2019

Guest Editor: Jiping Yue

Copyright (c) 2019 Zhihua Gao et al. This is an open access article distributed under the Creative Commons Attribution License, which permits unrestricted use, distribution, and reproduction in any medium, provided the original work is properly cited.

\begin{abstract}
Background. To find the potential intersections between the differentially expressed proteins and abnormally expressed genes in gastric cancer (GC) patients. Methods. Gastric cancer tissue and adjacent normal mucosa tissue were used for iTRAQ analysis. Gene ontology (GO), Kyoto Encyclopedia of Genes and Genomes (KEGG) pathway analysis, and protein-protein interaction (PPI) analysis were used to evaluate gene function. Western blotting and immunohistochemistry (IHC) were applied to verify the protein expression. Results. A total of 2770 proteins were identified, of which 147 proteins were upregulated and 159 proteins were downregulated. GO analysis revealed that the differentially expressed genes were mainly enriched for the terms "cellular process," "binding," and "cell." The results of the KEGG analysis showed that the most abundantly enriched proteins were involved in the "focal adhesion" pathway. The results of the PPI analysis showed that VCAM1 was located at the center of the PPI network. Western blotting and IHC analysis demonstrated that VCAM1, FLNA, VASP, CAV1, PICK1, and COL4A2 were differentially expressed in GC and adjacent normal tissues, which was consistent with the results of the iTRAQ analysis. Conclusion. In conclusion, 6 highly differentially expressed proteins were identified as novel differentially expressed proteins in human GC. This exploratory research may provide useful information for the treatment of gastric cancer in the clinic.
\end{abstract}

\section{Introduction}

Gastric cancer (GC) is a malignant tumor originating from the gastric mucosa. It is one of the most common digestive tract tumors. China is ranked as one of countries with a high incidence of gastric cancer. There are approximately 400,000 new cases of gastric cancer diagnosed in China each year, and the death toll is approximately 350,000, which accounts for $40 \%$ of the total number of GC cases worldwide [1-3]. The early diagnosis and treatment rate of gastric cancer in China is low, and the significantly low rate of $10 \%$ is far lower than that in Japan and South Korea $[4,5]$. The death rate for gastric cancer ranks third among the rates for malignant tumors.
The early diagnosis and treatment rates of gastric cancer in China are relatively low, and the diagnosis of gastric cancer is made mostly in the advanced stages, resulting in a high mortality rate for gastric cancer. The early diagnosis of gastric cancer is an important step to improve the clinical curative effects of GC treatment and to save lives.

Surgery is the main treatment method for gastric cancer. Chemotherapy is the main treatment method for patients who miss the opportunity for surgery or for patients with recurrence and metastatic GC after surgery. Drug resistance (or drug insensitivity) could lead to the failure of chemotherapy, which is one of the major problems that plagues most patients during treatment [6-8]. Multidrug resistance 
(MDR) is the main reason for the failure of chemotherapy in gastric cancer [9]. The screening of MDR-related molecules for gastric cancer and potential markers to predict the extent of drug resistance are fundamental for the improvement of drug therapy and drug development processes. With the rapid development of genomics and proteomics, screening of the tumor target is no longer limited to subtractive hybridization and gene chip methods, and proteomics has become a new method that is used for screening tumorrelated targets. One of the hot topics in proteomics research is the use of differential screening to explore the differentially expressed proteins in experimental cells (tissues) and control cells (tissues). Using this method, we explored the mediators of the upstream and downstream molecular pathways and elucidated the factors involved in the occurrence and development of disease.

The use of isobaric tags for relative and absolute quantitation with iTRAQ technology is a novel proteomics quantitative research technique used to conduct quantitative analysis in different samples simultaneously $[10,11]$. iTRAQ could screen for differential proteins with good quantitative effects and high repeatability. It has become an effective method for screening differentially expressed proteins in cancer research. In this study, we examined the differentially expressed proteins in gastric cancer tissues and normal gastric mucosa using iTRAQ technology to explore the mechanism of gastric cancer.

In this study, tumor gene detection was carried out in patients to determine the potential intersections between the differentially expressed proteins and the abnormally expressed genes based on a literature search and clinical medication analysis results. This exploratory research could provide useful information for the treatment of gastric cancer in the clinic.

\section{Methods}

2.1. Clinical Samples. A total of 240 GC patients were recruited from the Affiliated Hospital of the Logistics Institute of the Chinese People's Armed Police Forces between October 2014 and September 2016. All patients were diagnosed with gastric cancer by pathological examination. All patients underwent surgical resection without any prior treatment. The flow chart showing the process of the recruitment of the study participants is shown in Figure 1. After obtaining informed consent, 6 gene detections were carried out to search for the potential intersections with abnormally expressed genes and proteins in these GC patients, and the gene detection results were also used for the individually targeted treatment of the patients. The study was approved and registered with the Ethics Committee of the Affiliated Hospital of the Logistics Institute of the Chinese People's Armed Police Forces in September 2014. The Ethics Committee approved the data collection and the related screening, treatment, and follow-up of these patients. Written informed consent was obtained from all subjects. All work was undertaken according to the provisions of the Declaration of Helsinki.
2.2. Sample Collection and Protein Extraction. The gastric cancer tissue and adjacent normal gastric mucosa tissue were resected from GC patients. The normal gastric mucosa tissue was obtained $10-15 \mathrm{~cm}$ away from the tumor center and pathologically confirmed as normal gastric mucosa. The partially resected tissue was fixed with $4 \%$ formaldehyde, and the rest was stored in liquid nitrogen immediately prior to protein extraction and other follow-up analyses.

For protein extraction, the thawed tissue $(150 \mathrm{mg})$ was cut into pieces with scissors. Six hundred microliters of RIPA lysis buffer (Thermo Fischer Scientific, Waltham, MA, USA) and $10 \mu \mathrm{L}$ PMSF (Thermo) were added to the tissues. The tissue was ground on ice. The suspension was mixed and processed by a homogenizer $(24 \times 2,6.0 \mathrm{M} / \mathrm{S}$, MP FastPrep-24, MP Biomedicals, Santa Ana, CA, USA) twice for $60 \mathrm{~s}$. The suspension was treated by ultrasound ( $80 \mathrm{~W}, 10 \mathrm{~s}, 16$ times) on ice and then placed in a boiling water bath for 10$15 \mathrm{~min}$, followed by centrifugation at $14,000 \mathrm{~g}$ for $15 \mathrm{~min}$. The suspension was filtered through a $0.22 \mu \mathrm{m}$ filter membrane, and the filtrate was collected. The protein quantitation of each specimen was performed by the BCA method. In the GC group or the normal control group, the samples were mixed according to the principle that the protein extracted from each specimen was added to the same amount of protein; finally, the total protein samples of the GC group and the normal control group were obtained. The total protein samples of the GC group and normal control group were collected and stored at $-80^{\circ} \mathrm{C}$.

2.3. ITRAQ Labeling. The mixed protein was reduced by alkylation and processed by enzymolysis. The sample $(100 \mu \mathrm{g})$ was labeled with iTRAQ reagents (CIEX, Framingham, MA, USA) for $2 \mathrm{~h}$. The iTRAQ-labeled samples were reconstituted in $4 \mathrm{~mL}$ buffer $\mathrm{A}\left(10 \mathrm{mM} \mathrm{KH}_{2} \mathrm{PO}_{4}\right.$ in $25 \%$ acetonitrile at $\mathrm{pH} 3.0)$ and loaded onto a $5 \mu \mathrm{m}$ particle size, $4.6 \times 250 \mathrm{~mm}$ Ultremex SCX column (Phenomenex). The samples were eluted at a rate of $1 \mathrm{~mL} / \mathrm{min}$ with a gradient consisting of $100 \%$ buffer A from $0 \mathrm{~min}$ to $25 \mathrm{~min}, 0 \%-$ $10 \%$ buffer $\mathrm{B}\left(10 \mathrm{mM} \mathrm{KH}_{2} \mathrm{PO}_{4}\right.$ in $25 \%$ acetonitrile/500 mM $\mathrm{KCl}$ at $\mathrm{pH} 3.0$ ) from $25 \mathrm{~min}$ to $32 \mathrm{~min}, 10 \%-20 \%$ buffer $\mathrm{B}$ from $32 \mathrm{~min}$ to $42 \mathrm{~min}, 20 \%-45 \%$ buffer B from $42 \mathrm{~min}$ to $47 \mathrm{~min}, 45 \%-100 \%$ buffer B from $47 \mathrm{~min}$ to $52 \mathrm{~min}$, and $100 \%$ buffer B from $52 \mathrm{~min}$ to $60 \mathrm{~min}$. Then, the system was equilibrated with buffer A for $10 \mathrm{~min}$ prior to the next injection. The absorbance at $214 \mathrm{~nm}$ was monitored during the elution, and fractions were collected every $1 \mathrm{~min}$. After lyophilization, a C18 cartridge was used for desalting.

2.4. nanoLC-MALDI-TOF/TOF MS/MS Assay. All samples were analyzed using the Easy nLC HPLC system (Thermo Fisher) combined with a $\mathrm{Q}$ Exactive mass spectrometer (Thermo Fisher). The samples were treated with a Thermo Scientific EASY Column SC200 $(10 \mathrm{~cm} \times 75 \mu \mathrm{m}, 3 \mu \mathrm{m}$ C18A2) for $60 \mathrm{~min}$ with a gradient consisting of $0 \%-35 \%$ buffer B $(84 \%$ acetonitrile $/ 0.1 \%$ formic acid $)$ from $0 \mathrm{~min}$ to $50 \mathrm{~min}, 35 \%-100 \%$ buffer B from $50 \mathrm{~min}$ to $55 \mathrm{~min}$, and $100 \%$ buffer B from $55 \mathrm{~min}$ to $60 \mathrm{~min}$. Buffer A was a $0.1 \%$ formic acid solution. 


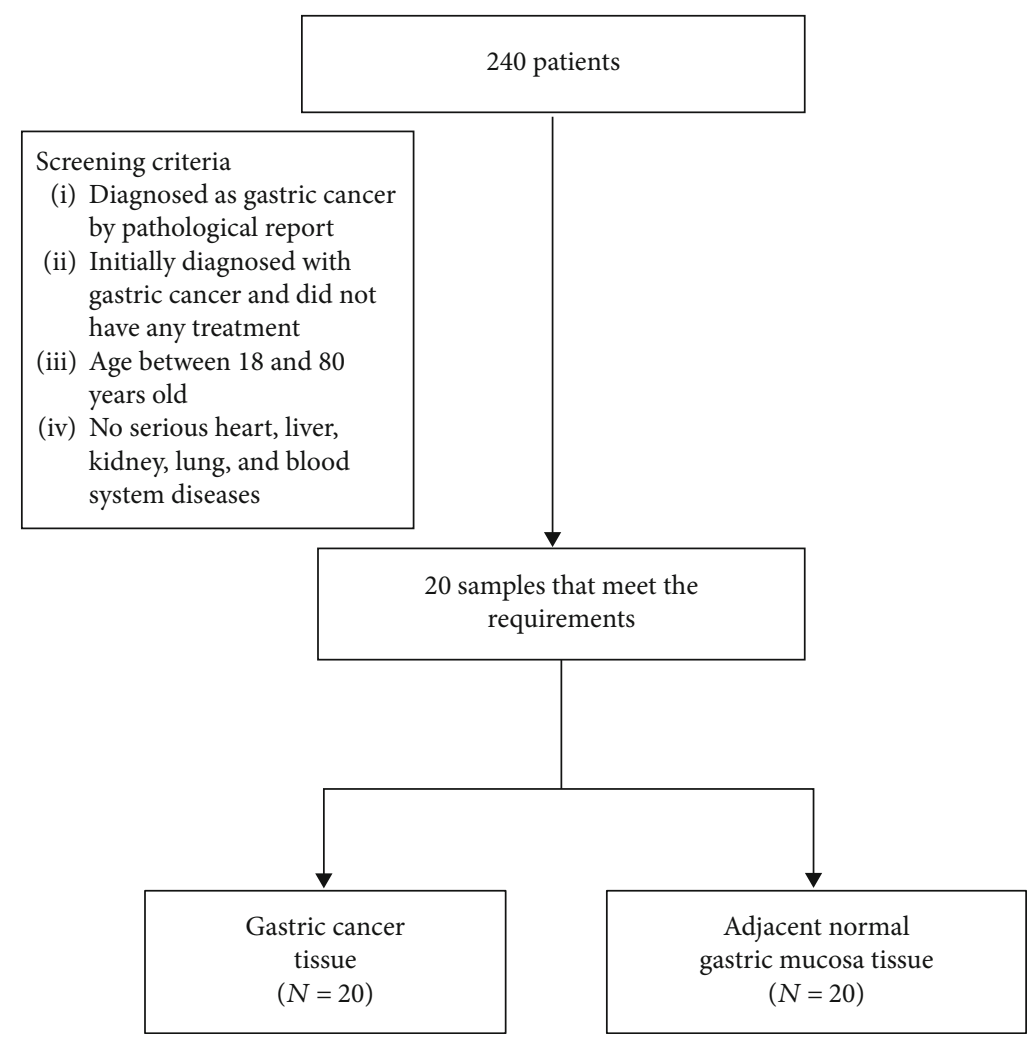

FIGURE 1: STARD flowchart of the process used to recruit the study participants.

The sample was chromatographically analyzed by mass spectrometry using a Q Exactive mass spectrometer. The analysis time was $60 \mathrm{~min}$, and the detection mode was positive ion mode. The parent ion scanning ranged from $300 \mathrm{~m} / z$ to $1800 \mathrm{~m} / z$. The primary mass spectrometer resolution was 70,000 at $200 \mathrm{~m} / z$. The AGC (automatic gain control) target was 1e6, and the maximum IT was $50 \mathrm{~ms}$. The dynamic exclusion was $60.0 \mathrm{~s}$. The mass-to-charge ratio of the polypeptide and polypeptide fragments was determined using the following parameters: 20 fragments were acquired after each full scan, the MS2 activation type was HCD, the isolation window was $2 \mathrm{~m} / z$, the secondary mass spectrometer resolution was 17,500 at $200 \mathrm{~m} / z$, the normalized collision energy was $30 \mathrm{eV}$, and the underfill was $0.1 \%$. Mascot 2.2 and Proteome Discoverer 1.4 software were used for the data analysis.

2.5. Gene Ontology (GO), Protein-Protein Interaction (PPI), and Kyoto Encyclopedia of Genes and Genomes (KEGG) Pathway Analyses. The differentially expressed genes were annotated using the Database for Annotation, Visualization, and Integrated Discovery (DAVID; http://david.ncifcrf.gov) (version 6.7), and the enriched biological metabolic pathways were determined using the Kyoto Encyclopedia of Genes and Genomes (KEGG) (http://www.genome.jp/kegg/ ). A $P$ value $<0.05$ was considered to indicate a significant correlation. The PPI network was assessed using the Search Tool for the Retrieval of Interacting Genes database (STRING, https://string-db.org/) and visualized using Cytoscape software according to the previous reference [12-14].
2.6. Western Blotting. Total proteins were extracted using RIPA lysis buffer (Pierce, Invitrogen, Gaithersburg, MD, USA). The concentration of the extracted protein was determined by a BCA assay. The total protein was separated by $12 \%$ sodium dodecyl sulfate-polyacrylamide gel electrophoresis (SDS-PAGE), followed by transfer to a PVDF membrane (EMD Millipore, Billerica, MA, USA), which was blocked with $5 \%$ skim milk for $1 \mathrm{~h}$. The primary antibodies, anti-VCAM1 (1:1000 dilution, Cell Signaling Technology, MA, USA), anti-VASP (1:1000 dilution, Cell Signaling Technology), anti-PICK1 (1:1000 dilution, Cell Signaling Technology), anti-FLNA (1:1000 dilution, Cell Signaling Technology), anti-COL4A2 (1:1000 dilution, Cell Signaling Technology), anti-CAV1 (1:1000 dilution, Cell Signaling Technology), and anti-GAPDH (1:1000 dilution, Cell Signaling Technology), were added and incubated with the membranes at $4^{\circ} \mathrm{C}$ overnight. Then, the membranes were washed with PBS buffer and incubated with anti-rabbit IgG antibody ( $1: 10,000$ dilution, Cell Signaling Technology) at $37^{\circ} \mathrm{C}$ for $45 \mathrm{~min}$. An imaging system (Odyssey, LI-COR Biosciences, Lincoln, NE, USA) was used for the semiquantitative analysis. GAPDH was used as an internal control.

2.7. Immunohistochemistry (IHC) Assay. GC and control samples were fixed with $4 \%$ formaldehyde solution and embedded in paraffin. Then, the sections ( $5 \mu \mathrm{m}$ thickness) were incubated with $3 \% \mathrm{H}_{2} \mathrm{O}_{2}$ for $10 \mathrm{~min}$ at room temperature to eliminate endogenous peroxidase activity. The sections were blocked with $10 \%$ goat serum at room temperature for $10 \mathrm{~min}$. Then, the sections were incubated with 
TABLE 1: The top 50 proteins with upregulation multiples greater than 1.2-fold.

\begin{tabular}{|c|c|c|c|c|}
\hline $\mathrm{N}$ & Accession & Description & Up fold & $P$ value \\
\hline 1 & A0A087X079 & $\begin{array}{l}\text { Ig gamma-1 chain C region OS=Homo sapiens GN=IGHG1 PE=1 SV=1 } \\
\text { (A0A087X079_HUMAN) }\end{array}$ & 4.683184 & $1.29 E-25$ \\
\hline 2 & O14604 & $\begin{array}{l}\text { Thymosin beta-4, Y-chromosomal OS=Homo sapiens GN=TMSB4Y PE=1 SV=3 } \\
\text { (TYB4Y_HUMAN) }\end{array}$ & 3.016063 & $8.25 E-14$ \\
\hline 3 & P31327 & $\begin{array}{l}\text { Carbamoyl-phosphate synthase (ammonia), mitochondrial OS=Homo } \\
\text { sapiens GN=CPS1 PE=1 SV=2 (CPSM_HUMAN) }\end{array}$ & 2.721231 & $1.33 E-11$ \\
\hline 4 & A1A5C5 & $\mathrm{RRBP} 1$ protein $\mathrm{OS}=$ Homo sapiens $\mathrm{GN}=\mathrm{RRBP} 1 \mathrm{PE}=2 \mathrm{SV}=1$ (A1A5C5_HUMAN) & 2.547532 & $2.67 E-10$ \\
\hline 5 & P25815 & Protein S100-P OS=Homo sapiens GN=S100P PE=1 SV=2 (S100P_HUMAN) & 2.528605 & $3.71 E-10$ \\
\hline \multirow[t]{2}{*}{6} & P0DMU9 & $\begin{array}{l}\text { Cancer/testis antigen family } 45 \text { member A10 OS=Homo sapiens GN=CT45A10 PE=2 SV=1 } \\
\text { (CT45A_HUMAN) }\end{array}$ & 2.486112 & $7.72 E-10$ \\
\hline & Q86XP6 & Gastrokine-2 OS=Homo sapiens GN=GKN2 PE=1 SV=2 (GKN2_HUMAN) & 2.283884 & $2.51 E-08$ \\
\hline 8 & B3KY79 & $\begin{array}{l}\text { cDNA FLJ46620 fis, clone TLUNG2000654, highly similar to keratin, type II cytoskeletal } 7 \\
\text { OS=Homo sapiens PE=2 SV=1 (B3KY79_HUMAN) }\end{array}$ & 2.215252 & $8.09 E-08$ \\
\hline 9 & A8K2T5 & $\begin{array}{l}\text { cDNA FLJ77047, highly similar to Homo sapiens zinc finger protein } 217 \text { (ZNF217), } \\
\text { mRNA (fragment) OS=Homo sapiens PE=2 SV=1 (A8K2T5_HUMAN) }\end{array}$ & 2.209209 & $8.97 E-08$ \\
\hline 10 & B4E2T6 & $\begin{array}{l}\text { cDNA FLJ58231, highly similar to NMDA receptor-regulated protein } 1 \\
\text { OS=Homo sapiens } \mathrm{PE}=2 \mathrm{SV}=1 \text { (B4E2T6_HUMAN) }\end{array}$ & 2.045548 & $1.42 E-06$ \\
\hline 11 & D6CHE9 & Proteinase 3 OS=Homo sapiens GN=PRTN3 PE=2 SV=1 (D6CHE9_HUMAN) & 2.038724 & $1.59 E-06$ \\
\hline 12 & H0YJL6 & $\begin{array}{l}\text { Ena/VASP-like protein (fragment) OS=Homo sapiens GN=EVL PE=1 SV=1 } \\
\text { (H0YJL6_HUMAN) }\end{array}$ & 2.036708 & $1.64 E-06$ \\
\hline 13 & Q5T619 & Zinc finger protein 648 OS=Homo sapiens GN=ZNF648 PE=2 SV=1 (ZN648_HUMAN) & 2.035727 & $1.67 E-06$ \\
\hline 14 & Q658S4 & $\begin{array}{l}\text { Putative uncharacterized protein DKFZp666N164 (fragment) OS=Homo sapiens } \\
\text { GN=DKFZp666N164 PE=2 SV=1 (Q658S4_HUMAN) }\end{array}$ & 1.990709 & $3.53 E-06$ \\
\hline 15 & B2RBL3 & Thymidine phosphorylase OS=Homo sapiens PE=2 SV=1 (B2RBL3_HUMAN) & 1.988453 & $3.66 E-06$ \\
\hline 16 & P98088 & Mucin-5AC OS=Homo sapiens GN=MUC5AC PE=1 SV=4 (MUC5A_HUMAN) & 1.981462 & $4.11 E-06$ \\
\hline 17 & Q9HD89 & Resistin OS=Homo sapiens GN=RETN PE=1 SV=1 (RETN_HUMAN) & 1.949174 & $6.99 E-06$ \\
\hline 18 & B4DLS7 & $\begin{array}{l}\text { cDNA FLJ53454, highly similar to interferon-induced protein with tetratricopeptide repeats } 3 \\
\text { OS=Homo sapiens PE=2 SV=1 (B4DLS7_HUMAN) }\end{array}$ & 1.911231 & $1.30 E-05$ \\
\hline 19 & P06702 & Protein S100-A9 OS=Homo sapiens GN=S100A9 PE=1 SV=1 (S10A9_HUMAN) & 1.882936 & $2.06 E-05$ \\
\hline 20 & C9JKF7 & $\begin{array}{l}\text { Lymphocyte-specific protein } 1 \text { (fragment) OS=Homo sapiens GN=LSP1 PE=1 SV=1 } \\
\text { (C9JKF7_HUMAN) }\end{array}$ & 1.878033 & $2.23 E-05$ \\
\hline 21 & P52566 & $\begin{array}{l}\text { Rho GDP-dissociation inhibitor } 2 \text { OS=Homo sapiens GN=ARHGDIB PE }=1 \mathrm{SV}=3 \\
\text { (GDIR2_HUMAN) }\end{array}$ & 1.843884 & $3.86 E-05$ \\
\hline 22 & P16402 & Histone H1.3 OS=Homo sapiens GN=HIST1H1D PE=1 SV=2 (H13_HUMAN) & 1.834376 & $4.49 E-05$ \\
\hline 23 & Q7Z351 & $\begin{array}{l}\text { Putative uncharacterized protein DKFZp686N02209 OS=Homo sapiens GN=DKFZp686N02209 } \\
\qquad \mathrm{PE}=2 \text { SV=1 (Q7Z351_HUMAN) }\end{array}$ & 1.82681 & $5.07 E-05$ \\
\hline 24 & D3DP16 & $\begin{array}{l}\text { Fibrinogen gamma chain, isoform CRA_a OS=Homo sapiens GN=FGG PE=4 SV=1 } \\
\text { (D3DP16_HUMAN) }\end{array}$ & 1.818705 & $5.77 E-05$ \\
\hline 25 & P40261 & $\begin{array}{l}\text { Nicotinamide N-methyltransferase OS=Homo sapiens GN=NNMT PE=1 SV=1 } \\
\text { (NNMT_HUMAN) }\end{array}$ & 1.792604 & $8.72 E-05$ \\
\hline 26 & B7Z747 & $\begin{array}{l}\text { cDNA FLJ51120, highly similar to matrix metalloproteinase-9 (EC 3.4.24.35) OS=Homo sapiens } \\
\qquad \mathrm{PE}=2 \mathrm{SV}=1 \text { (B7Z747_HUMAN) }\end{array}$ & 1.756301 & 0.000154 \\
\hline 27 & I1VZV6 & Hemoglobin alpha 1 OS=Homo sapiens GN=HBA1 PE=3 SV=1 (I1VZV6_HUMAN) & 1.755144 & 0.000157 \\
\hline 28 & P02792 & Ferritin light chain OS=Homo sapiens GN=FTL PE=1 SV=2 (FRIL_HUMAN) & 1.75021 & 0.000169 \\
\hline 29 & F5H5I5 & $\begin{array}{l}\text { ATP-binding cassette sub-family B member } 9 \text { (fragment) OS=Homo sapiens } \mathrm{GN}=\mathrm{ABCB} 9 \mathrm{PE}=4 \\
\qquad \mathrm{SV}=1 \text { (F5H5I5_HUMAN) }\end{array}$ & 1.746098 & 0.000181 \\
\hline 30 & Q6P4A8 & Phospholipase B-like 1 OS=Homo sapiens GN=PLBD1 PE=1 SV=2 (PLBL1_HUMAN) & 1.732104 & 0.000224 \\
\hline 31 & H0YJG9 & $\begin{array}{l}\text { Dehydrogenase/reductase SDR family member 2, mitochondrial (fragment) OS=Homo sapiens } \\
\text { GN=DHRS2 PE=1 SV=1 (H0YJG9_HUMAN) }\end{array}$ & 1.727996 & 0.000239 \\
\hline 32 & C9JZJ5 & $\begin{array}{l}\text { Melanoma-associated antigen } 4 \text { (fragment) OS=Homo sapiens GN=MAGEA4 } \\
\qquad \mathrm{PE}=1 \mathrm{SV}=7 \text { (C9JZJ5_HUMAN) }\end{array}$ & 1.717063 & 0.000283 \\
\hline 33 & P20591 & $\begin{array}{l}\text { Interferon-induced GTP-binding protein } \mathrm{Mx} 1 \mathrm{OS}=\text { Homo sapiens GN=MX1 } \\
\qquad \mathrm{PE}=1 \mathrm{SV}=4\left(\mathrm{MX} 1 \_ \text {HUMAN) }\right.\end{array}$ & 1.705117 & 0.00034 \\
\hline
\end{tabular}


TABle 1: Continued.

\begin{tabular}{|c|c|c|c|c|}
\hline $\mathrm{N}$ & Accession & Description & Up fold & $P$ value \\
\hline 34 & Q400J6 & $\begin{array}{l}\text { Arylamine } \mathrm{N} \text {-acetyltransferase (fragment) OS=Homo sapiens GN=NAT1 PE=2 SV=1 } \\
\text { (Q400J6_HUMAN) }\end{array}$ & 1.6983 & 0.000377 \\
\hline 35 & P80723 & Brain acid soluble protein 1 OS=Homo sapiens GN=BASP1 PE=1 SV=2 (BASP1_HUMAN) & 1.696699 & 0.000386 \\
\hline 36 & P05109 & Protein $\mathrm{S} 100-\mathrm{A} 8 \mathrm{OS}=$ Homo sapiens $\mathrm{GN}=\mathrm{S} 100 \mathrm{~A} 8 \mathrm{PE}=1 \mathrm{SV}=1$ (S10A8_HUMAN) & 1.684961 & 0.000462 \\
\hline 37 & B2MUD5 & Neutrophil elastase (fragment) OS=Homo sapiens GN=ELA2 PE=4 SV=1 (B2MUD5_HUMAN) & 1.681383 & 0.000487 \\
\hline 38 & P23381 & $\begin{array}{l}\text { Tryptophan-tRNA ligase, cytoplasmic OS=Homo sapiens GN=WARS PE=1 SV=2 } \\
\text { (SYWC_HUMAN) }\end{array}$ & 1.670288 & 0.000576 \\
\hline 39 & Q86YQ1 & $\begin{array}{c}\text { Hemoglobin alpha-2 (fragment) OS=Homo sapiens GN=HBA2 PE=3 SV=1 } \\
\text { (Q86YQ1_HUMAN) }\end{array}$ & 1.669802 & 0.000581 \\
\hline 40 & A0A0G2JMH6 & $\begin{array}{l}\text { HLA class II histocompatibility antigen, DR alpha chain OS=Homo sapiens GN=HLA-DRA } \\
\qquad \mathrm{PE}=1 \mathrm{SV}=1 \text { (A0A0G2JMH6_HUMAN) }\end{array}$ & 1.663235 & 0.000641 \\
\hline 41 & B4DVG3 & $\begin{array}{l}\text { cDNA FLJ53104, moderately similar to Homo sapiens } \mathrm{N} \text {-acetylneuraminate pyruvate lyase } \\
\text { (dihydrodipicolinate synthase) (NPL), mRNA OS=Homo sapiens } \mathrm{PE}=2 \mathrm{SV}=1 \\
\text { (B4DVG3_HUMAN) }\end{array}$ & 1.662357 & 0.000649 \\
\hline 42 & A0A140VJJ6 & Testicular tissue protein Li 70 OS=Homo sapiens PE=2 SV=1 (A0A140VJJ6_HUMAN) & 1.653489 & 0.000742 \\
\hline 43 & B4E0J9 & $\begin{array}{l}\text { cDNA FLJ57348, highly similar to Homo sapiens hexokinase domain containing } 1 \text { (HKDC1), } \\
\text { mRNA OS=Homo sapiens PE=2 SV=1 (B4E0J9_HUMAN) }\end{array}$ & 1.653261 & 0.000744 \\
\hline 44 & U6FVB0 & $\begin{array}{c}\text { Tyrosine-protein kinase receptor OS= Homo sapiens GN=CD74-Ntrk1 fusion gene PE=2 SV=1 } \\
\text { (U6FVB0_HUMAN) }\end{array}$ & 1.616527 & 0.001283 \\
\hline 45 & A2MYE1 & A30 (fragment) OS=Homo sapiens $\mathrm{PE}=4 \mathrm{SV}=1$ (A2MYE1_HUMAN) & 1.599301 & 0.001651 \\
\hline 46 & B4DVC2 & $\begin{array}{l}\text { cDNA FLJ51332, highly similar to HLA class II histocompatibility antigen, DMbeta chain } \\
\text { OS=Homo sapiens } \mathrm{PE}=2 \mathrm{SV}=1 \text { (B4DVC2_HUMAN) }\end{array}$ & 1.592926 & 0.001811 \\
\hline 47 & Q8IZI0 & $\begin{array}{l}\text { Hemoglobin beta chain variant Hb-I_Toulouse (fragment) OS=Homo sapiens GN=HBB PE=3 } \\
\qquad \text { SV=1 (Q8IZI0_HUMAN) }\end{array}$ & 1.592452 & 0.001823 \\
\hline 48 & Q6P1N7 & TAPBP protein OS=Homo sapiens GN=TAPBP PE=1 SV=1 (Q6P1N7_HUMAN) & 1.584238 & 0.002054 \\
\hline 49 & B4DNT5 & $\begin{array}{l}\text { cDNA FLJ60316, highly similar to Apolipoprotein-L1 OS=Homo sapiens PE=2 SV=1 } \\
\text { (B4DNT5_HUMAN) }\end{array}$ & 1.577475 & 0.002264 \\
\hline 50 & O15451 & $\begin{array}{c}\text { Proline and glutamic acid-rich nuclear protein isoform } \\
\text { (fragment) OS=Homo sapiens } \mathrm{PE}=2 \mathrm{SV}=2 \text { (O15451_HUMAN) }\end{array}$ & 1.576906 & 0.002282 \\
\hline
\end{tabular}

primary antibodies, including anti-CAV1 (1:1000 dilution, Cell Signaling Technology), anti-VASP (1:1000 dilution, Cell Signaling Technology), and anti-VCAM1 (1:1000 dilution, Cell Signaling Technology, MA, USA), at $37^{\circ} \mathrm{C}$ for $2 \mathrm{~h}$. After the application of the secondary antibody (anti-rabbit IgG antibody, $1: 10,000$ dilution, Cell Signaling Technology), the sections were incubated at $37^{\circ} \mathrm{C}$ for $30 \mathrm{~min}$. Subsequently, the DAB Plus Substrate Chromogen mixture was added, and the sections were incubated for $10 \mathrm{~min}$.

The Human Protein Atlas (http://www.proteinatlas.org/) was used to validate the expression of the six genes in GC tissue.

2.8. Statistical Analysis. SPSS 22.0 statistical software was used for the statistical analysis. The values were expressed as the mean \pm standard deviation (SD) and compared using Student's $t$ test or the Wilcoxon/Mann-Whitney rank sum test. $P<0.05$ was considered to indicate a statistically significant difference.

\section{Results}

3.1. iTRAQ and GO Analysis. Compared to adjacent normal tissues, 2770 proteins were differentially expressed in tumor tissues, of which 147 were upregulated by more than 1.2-fold
$(P<0.05)$ and 159 were downregulated by more than 0.8 fold $(P<0.05)$. The top 50 proteins upregulated by more than 1.2-fold and downregulated by more than 0.8 -fold are shown in Tables 1 and 2, respectively. Subsequently, GO analysis was applied to analyze the differentially expressed genes. The differentially expressed genes were enriched in various molecular functions (MF), biological processes (BP), and cellular component terms (CC) (Figure 2). "Cellular process," "binding," and "cell" were the most enriched terms in BP, MF, and CC, respectively (Figure 2).

3.2. KEGG Pathway and Protein-Protein Interaction (PPI) Analysis. The KEGG analysis revealed differential protein enrichment in 41 KEGG metabolic pathways (Table 3). The top 20 metabolic pathways are shown in Figure 3(a), and the most abundantly enriched protein was involved in the "focal adhesion" pathway. The differentially expressed proteins involved in "focal adhesion" pathways included COL6A3, MYLK, VASP, FLNC, FLNA, ACTN2, PARVA, ACTN1, ITGA5, CAV1, VCL, PICK1, COL4A2, and ITGA1. The detailed information about these 14 proteins is listed in Table 4. In addition, the results of the PPI analysis showed that VCAM1 was located at the center of the PPI network (Figure 3(b)). 
TABLE 2: The top 50 proteins with downregulation folds less than 0.8 -fold.

\begin{tabular}{|c|c|c|c|c|}
\hline $\mathrm{n}$ & Accession & Description & $\begin{array}{l}\text { Down } \\
\text { fold }\end{array}$ & $P$ value \\
\hline 1 & O60844 & 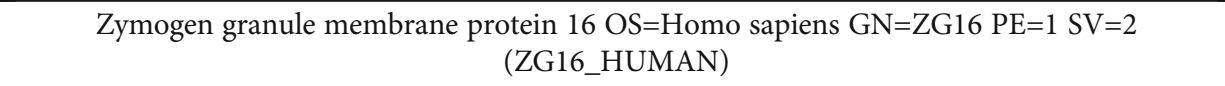 & 0.198959 & $3.21 E-19$ \\
\hline 2 & E1CKY7 & $\begin{array}{l}\text { Protein phosphatase } 1 \text { regulatory subunit } 12 \mathrm{~B} \text { OS=Homo sapiens } \mathrm{GN}=\mathrm{sm}-\mathrm{M} 20 \mathrm{PE}=1 \mathrm{SV}=1 \\
\text { (E1CKY7_HUMAN) }\end{array}$ & 0.254236 & $2.81 E-14$ \\
\hline 3 & Q9BYX7 & $\begin{array}{l}\text { Putative beta-actin-like protein } 3 \text { OS=Homo sapiens GN=POTEKP PE=5 SV=1 } \\
\text { (ACTBM_HUMAN) }\end{array}$ & 0.260689 & $8.13 E-14$ \\
\hline 4 & P51911 & Calponin-1 OS=Homo sapiens GN=CNN1 PE=1 SV=2 (CNN1_HUMAN) & 0.262319 & $1.06 E-13$ \\
\hline 5 & B7Z9B7 & $\begin{array}{l}\text { cDNA FLJ54732, moderately similar to sorbin and SH3 domain-containing protein } 1 \\
\text { OS=Homo sapiens } \mathrm{PE}=2 \mathrm{SV}=1 \text { (B7Z9B7_HUMAN) }\end{array}$ & 0.315502 & $1.42 E-10$ \\
\hline 6 & B4E1Q7 & $\begin{array}{l}\text { cDNA FLJ57294, highly similar to lipoamide acyltransferase component of branched-chain } \\
\text { alpha-keto acid dehydrogenase complex, mitochondrial (EC 2.3.1.168) OS=Homo sapiens PE=2 } \\
\text { SV=1 (B4E1Q7_HUMAN) }\end{array}$ & 0.339832 & $1.93 E-09$ \\
\hline 7 & Q9BTA4 & $\begin{array}{l}\text { Epididymis secretory protein Li } 286 \text { (fragment) OS=Homo sapiens GN=HEL-S-286 PE=2 SV=1 } \\
\text { (Q9BTA4_HUMAN) }\end{array}$ & 0.342304 & $2.47 E-09$ \\
\hline 8 & A5Z217 & Mutant desmin OS=Homo sapiens PE=2 SV=1 (A5Z217_HUMAN) & 0.382163 & $8.56 E-08$ \\
\hline 9 & A5A3E0 & $\begin{array}{l}\text { POTE ankyrin domain family member F OS=Homo sapiens GN=POTEF PE=1 SV=2 } \\
\text { (POTEF_HUMAN) }\end{array}$ & 0.387963 & $1.35 E-07$ \\
\hline 10 & Q96JG9 & Zinc finger protein 469 OS=Homo sapiens GN=ZNF469 PE=2 SV=3 (ZN469_HUMAN) & 0.395397 & $2.38 E-07$ \\
\hline 11 & P08217 & $\begin{array}{l}\text { Chymotrypsin-like elastase family member 2A OS=Homo sapiens GN=CELA2A PE=1 SV=1 } \\
\text { (CEL2A_HUMAN) }\end{array}$ & 0.398866 & $3.08 E-07$ \\
\hline 12 & P07098 & Gastric triacylglycerol lipase OS=Homo sapiens GN=LIPF PE=1 SV=1 (LIPG_HUMAN) & 0.405473 & $4.96 E-07$ \\
\hline 13 & B7Z6U8 & $\begin{array}{l}\text { cDNA FLJ53665, highly similar to four and a half LIM domains protein } 1 \text { OS=Homo sapiens } \\
\qquad \mathrm{PE}=2 \mathrm{SV}=1 \text { (B7Z6U8_HUMAN) }\end{array}$ & 0.408392 & $6.09 E-07$ \\
\hline 14 & P12277 & Creatine kinase B-type OS=Homo sapiens GN=CKB PE=1 SV=1 (KCRB_HUMAN) & 0.409014 & $6.36 E-07$ \\
\hline 15 & P0CG38 & $\begin{array}{l}\text { POTE ankyrin domain family member I OS=Homo sapiens GN=POTEI PE=3 SV=1 } \\
\text { (POTEI_HUMAN) }\end{array}$ & 0.409772 & $6.71 E-07$ \\
\hline 16 & B7Z7M8 & $\begin{array}{l}\text { cDNA FLJ60950, highly similar to hydroxymethylglutaryl-CoA synthase, } \\
\text { mitochondrial (EC 2.3.3.10) OS=Homo sapiens PE=2 SV=1 (B7Z7M8_HUMAN) }\end{array}$ & 0.419918 & $1.33 E-06$ \\
\hline 17 & P35749 & Myosin-11 OS=Homo sapiens GN=MYH11 PE=1 SV=3 (MYH11_HUMAN) & 0.420775 & $1.41 E-06$ \\
\hline 18 & O15061 & Synemin OS=Homo sapiens GN=SYNM PE=1 SV=2 (SYNEM_HUMAN) & 0.430091 & $2.57 E-06$ \\
\hline 19 & P68032 & Actin, alpha cardiac muscle 1 OS=Homo sapiens GN=ACTC1 PE=1 SV=1 (ACTC_HUMAN) & 0.437479 & $4.06 E-06$ \\
\hline 20 & P26678 & Cardiac phospholamban OS=Homo sapiens GN=PLN PE=1 SV=1 (PPLA_HUMAN) & 0.440292 & $4.81 E-06$ \\
\hline 21 & Q15124 & $\begin{array}{l}\text { Phosphoglucomutase-like protein } 5 \text { OS=Homo sapiens GN=PGM5 PE=1 SV=2 } \\
\text { (PGM5_HUMAN) }\end{array}$ & 0.442845 & $5.60 E-06$ \\
\hline 22 & B4DTX5 & $\begin{array}{l}\text { cDNA FLJ60072, highly similar to Homo sapiens sorbin and SH3 domain containing } 1 \text { (SORBS1), } \\
\text { transcript variant } 6, \text { mRNA OS=Homo sapiens } \mathrm{PE}=2 \mathrm{SV}=1 \text { (B4DTX5_HUMAN) }\end{array}$ & 0.444007 & $6.00 E-06$ \\
\hline 23 & B3KW93 & $\begin{array}{l}\text { Sodium/potassium-transporting ATPase subunit alpha OS=Homo sapiens } \mathrm{PE}=2 \mathrm{SV}=1 \\
\text { (B3KW93_HUMAN) }\end{array}$ & 0.446979 & $7.14 E-06$ \\
\hline 24 & F8VPF3 & $\begin{array}{l}\text { Myosin light polypeptide } 6 \text { (fragment) OS=Homo sapiens GN=MYL6 PE=1 SV=1 } \\
\text { (F8VPF3_HUMAN) }\end{array}$ & 0.448822 & $7.94 E-06$ \\
\hline 25 & Q9NR12 & $\begin{array}{l}\text { PDZ and LIM domain protein } 7 \text { OS=Homo sapiens GN=PDLIM7 PE=1 SV=1 } \\
\text { (PDLI7_HUMAN) }\end{array}$ & 0.455034 & $1.13 E-05$ \\
\hline 26 & Q01995 & Transgelin OS=Homo sapiens GN=TAGLN PE=1 SV=4 (TAGL_HUMAN) & 0.456778 & $1.24 E-05$ \\
\hline 27 & A0A024R5W6 & $\begin{array}{c}\text { Tropomyosin } 1 \text { (alpha), isoform CRA_a OS=Homo sapiens GN=TPM1 PE=3 SV=1 } \\
\text { (A0A024R5W6_HUMAN) }\end{array}$ & 0.458474 & $1.37 E-05$ \\
\hline 28 & Q63ZY3 & $\begin{array}{l}\text { KN motif and ankyrin repeat domain-containing protein } 2 \text { OS=Homo sapiens GN=KANK2 } \\
\qquad \mathrm{PE}=1 \mathrm{SV}=1 \text { (KANK2_HUMAN) }\end{array}$ & 0.461142 & $1.58 E-05$ \\
\hline 29 & E9PIE4 & $\begin{array}{c}\text { Mitochondrial carrier homolog } 2 \text { (fragment) OS=Homo sapiens GN=MTCH2 PE=1 SV=7 } \\
\text { (E9PIE4_HUMAN) }\end{array}$ & 0.462079 & $1.66 E-05$ \\
\hline 30 & Q16853 & $\begin{array}{l}\text { Membrane primary amine oxidase OS=Homo sapiens } \mathrm{GN}=\mathrm{AOC} 3 \mathrm{PE}=1 \mathrm{SV}=3 \\
\text { (AOC3_HUMAN) }\end{array}$ & 0.465486 & $2.00 E-05$ \\
\hline
\end{tabular}


TABLE 2: Continued.

\begin{tabular}{|c|c|c|c|c|}
\hline$n$ & Accession & Description & $\begin{array}{c}\text { Down } \\
\text { fold }\end{array}$ & $P$ value \\
\hline 31 & Q15746 & $\begin{array}{l}\text { Myosin light chain kinase, smooth muscle OS=Homo sapiens GN=MYLK PE }=1 \text { SV=4 } \\
\text { (MYLK_HUMAN) }\end{array}$ & .466825 & $14 E-05$ \\
\hline 32 & B3KUD6 & $\begin{array}{l}\text { cDNA FLJ39634 fis, clone SMINT2002689, highly similar to SMOOTHELIN OS=Homo sapiens } \\
\qquad \text { PE=2 SV=1 (B3KUD6_HUMAN) }\end{array}$ & 0.467199 & 2.1 \\
\hline 33 & A0A024R5N4 & $\begin{array}{l}\text { WD repeat domain 71, isoform CRA_a OS=Homo sapiens GN=WDR71 PE=4 SV=1 } \\
\text { (A0A024R5N4_HUMAN) }\end{array}$ & 0.467661 & $2.24 E-($ \\
\hline 34 & P68133 & Actin, alpha skeletal muscle OS=Homo sapiens GN=ACTA1 PE=1 SV=1 (ACTS_HUMAN) & 0.467865 & $5 E-05$ \\
\hline 35 & K7EM16 & $\begin{array}{l}\text { Vasodilator-stimulated phosphoprotein (frag } \\
\text { (K7EM })\end{array}$ & 0.471806 & 2 \\
\hline 36 & B4DWU6 & $\begin{array}{l}\text { cDNA FLJ51361, highly similar to keratin, typ } \\
\text { (B4DWL }\end{array}$ & 0.474248 & 3 \\
\hline 37 & Q14315 & Filamin-C OS=Homo sapiens GN=FLNC PE $=1 \mathrm{SV}=3$ (FLNC_HUMAN) & 0.478864 & $3.98 E-05$ \\
\hline 38 & O75795 & $\begin{array}{l}\text { UDP-glucuronosyltransferase } 2 \mathrm{~B} 17 \text { OS=1 } \\
\text { (UDB17 }\end{array}$ & 0.486547 & $5.80 E-05$ \\
\hline 39 & B2RTX2 & $\begin{array}{l}\text { Palladin, cytoskeletal associated protein } \\
\text { (B2RTX }\end{array}$ & 0.491737 & E-05 \\
\hline 40 & G3 V144 & $\begin{array}{l}\text { SH3 and PX domain-containing protein 2B } \\
\text { (G3 V14 }\end{array}$ & 0.492826 & $7.81 E-05$ \\
\hline 41 & Q05682 & Caldesmon OS=Homo sapiens $\mathrm{GN}=\mathrm{CALI}$ & 0.498478 & 0.000101 \\
\hline 42 & Q99795 & Cell surface A33 antigen OS=Homo sapiens GN=GPA33 PE=1 SV=1 (GPA33_HUMAN) & 0.499929 & 0.000108 \\
\hline 43 & P21333 & Filamin-A OS=Homo sapiens GN=FLNA PE=1 SV=4 (FLNA_HUMAN) & 0.502317 & 0.000121 \\
\hline 44 & B7Z964 & $\begin{array}{r}\text { Sarcolemmal membrane-associated protein OS= } \\
\text { (B7Z964_HUI }\end{array}$ & 0.503373 & 0.000127 \\
\hline 45 & A0A142CHG9 & GO2-q chimeric G-protein OS=Homo sapiens PE=2 SV=1 (A0A142CHG9_HUMAN) & 0.503463 & 0.000127 \\
\hline 46 & A9LSU1 & Type IV collagen alpha 1 (fragment) OS=Homo sapiens PE=2 SV=1 (A9LSU1_HUMAN) & 0.504429 & 0.000133 \\
\hline 47 & B3КM36 & $\begin{array}{l}\text { cDNA FLJ10153 fis, clone HEMBA1003417, highly similar to BAG family molecular chaperone } \\
\text { regulator } 2 \text { OS=Homo sapiens PE=2 SV=1 (B3KM36_HUMAN) }\end{array}$ & 0.509395 & 0.000165 \\
\hline 48 & Q9UMK6 & Dystrophin (fragment) OS=Homo sapiens GN=DMD PE=4 SV=1 (Q9UMK6_HUMAN) & 0.517995 & 0.000238 \\
\hline 49 & P10645 & Chromogranin-A OS=Homo sapiens GN=CHGA PE=1 SV=7 (CMGA_HUMAN) & 0.528393 & 0.000364 \\
\hline 50 & A8K2W3 & cDNA FLJ78516 OS=Homo sapiens PE=2 SV=1 (A8K2W3_HUMAN) & 0.530959 & 0.000403 \\
\hline
\end{tabular}

3.3. Verification of the Differentially Expressed Proteins Involved in the "Focal Adhesion" Pathway and Located at the Center of the PPI Network. Western blot assays were performed to measure the expression levels of VCAM1 and 5 other proteins (FLNA, VASP, CAV1, PICK1, and COL4A2) enriched in the "focal adhesion" pathway in GC and adjacent normal tissues. As shown in Figure 4, the results of Western blotting were consistent with the trends revealed by the iTRAQ assay. Furthermore, the expression levels of VASP (highest enrichment in the "focal adhesion" pathway), VCAM1 (located at the center of the PPI network) and CAV1 (related to the metastasis, proliferation, and aggregation of GC cells) were detected by IHC. The results showed that compared with their expression levels in adjacent normal tissues, CAV1 and VASP were downregulated in GC tissues $(P<0.001$, Figure 5), while VCAM1 was upregulated in GC tissues $(P<0.001$, Figure 5$)$. For validation of the identified differentially expressed proteins, the Human Protein Atlas database was searched to analyze the expression of VCAM1, FLNA, VASP, CAV1, PICK1, and COL4A2 in GC and adjacent normal tissues. As shown in Figure 6, the trends were consistent with the results of Western blotting and iTRAQ analysis. We speculated that the downregulation of COL4A2 outside the cell may downregulate the expression of CAV1 in the cell membrane through cell signaling, thereby affecting the intracellular expression of FLNA, VASP, and PICK1. We generated a simple activity flowchart of these proteins in Figure 7.

\section{Discussion}

In this study, most of the patients were already diagnosed with advanced gastric cancer. Their pathological differentiation was poor. Differentiated tumor cells have significant differences compared to normal gastric mucosa cells. The proliferation and differentiation abilities of these immature tumor cells were much higher than those of early gastric cancer cells. Thus, the overall condition and prognosis of the patients were poor. Due to recent progress in drug treatment, the therapeutic effect of chemotherapy, especially targeted drugs, in the treatment of gastric cancer has been improved. However, there are still many clinical problems that need to 


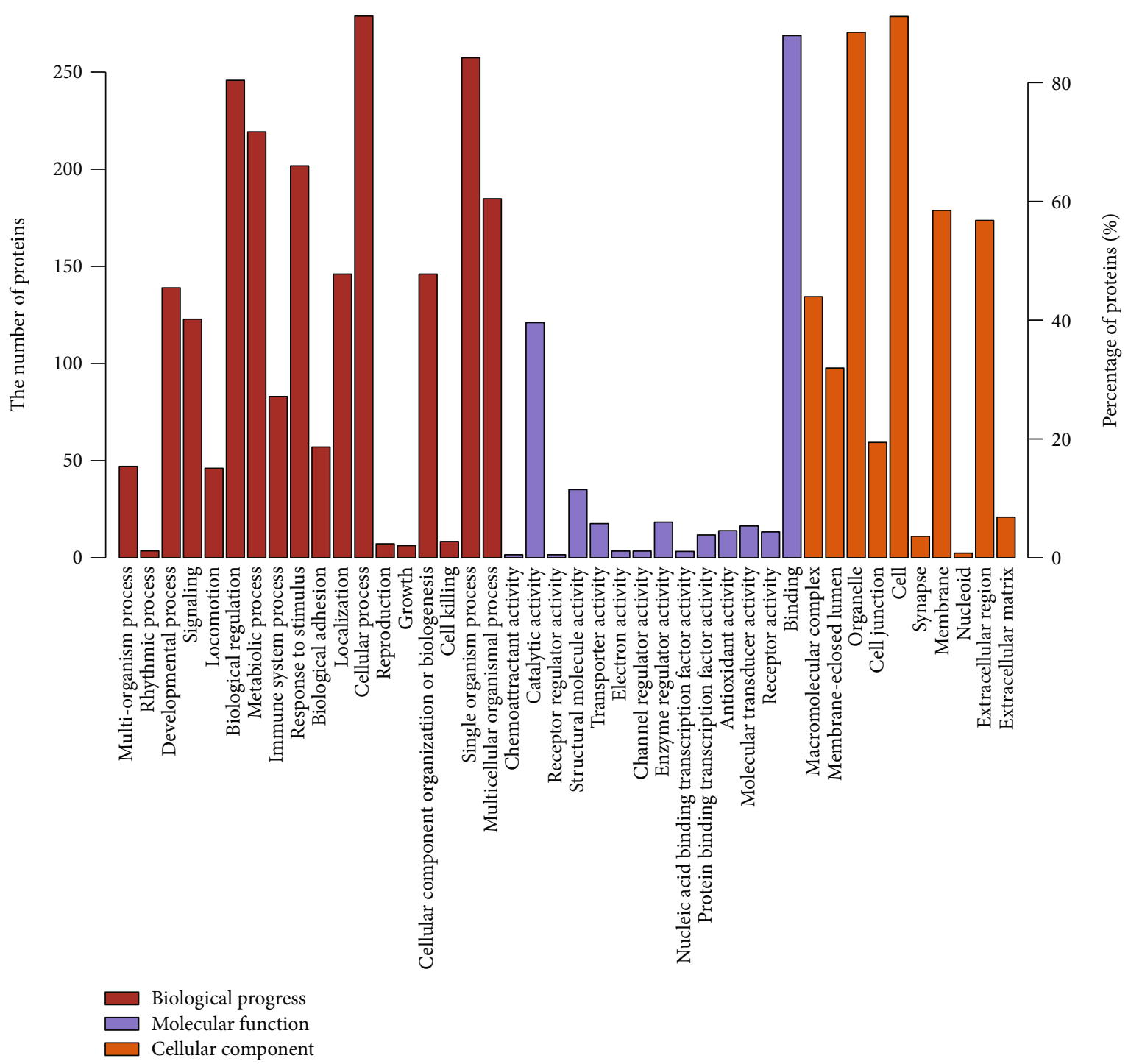

Figure 2: GO analysis of the differentially expressed genes. The differentially expressed proteins were enriched in molecular function (MF), biological process (BP), and cellular component (CC) terms.

be solved. We collected the resected GC samples, tested the differentially expressed proteins and genes in response to individual treatments, and attempted to explore the occurrence and development of tumors from the perspective of proteomics and gene changes and to determine the interactions between proteins and genes. We found only an interaction between TOPO IIa and filamin A (FLNA), and no other intersection has yet been found.

We speculate that the main reason for this is that we did not analyze these resected samples according to their Lauren classification. The GC samples from recruited patients were combined according to intestinal type, diffuse type, and mixed type for the iTRAQ analysis. Tan et al. [15] analyzed the gene expression profiles of 37 gastric cancer cell lines. They finally found 171 gene chips and divided them into the gastric intestinal (G-INT) and gastric diffuse subtypes (G-DIF). Further in vitro drug sensitivity tests demonstrated that cells of the G-INT type are sensitive to 5-FU and oxaliplatin. In addition, cells of the G-DIF type are sensitive to cis- platin. However, based on the pathological types of gastric cancer and the use of genotyping to guide evidence-based medicine, treatment options are very limited. However, this is the only method available for the individualized treatment of gastric cancer.

To date, there are several mechanisms of multidrug resistance (MDR) in tumors that have been identified. (1) Intracellular drugs are discharged to the outside of the cell membrane by the ABC (ATP-binding cassette) transporter protein family, and the accumulation of intracellular drugs is reduced. (2) The cytotoxicity of chemotherapy drugs is reduced by multiple detoxification molecules. (3) The concentration of drugs is reduced by exocytosis in cells. (4) The abnormal distribution or the change in the number of molecular targets causes drugs to lose their function. (5) The antiapoptotic ability of tumors is enhanced by molecular apoptosis.

FLNA, also called filamin A, plays important roles in the formation and function of the cytoskeleton. Studies have 
TABLE 3: Differential protein enrichment in 41 KEGG metabolic pathways.

\begin{tabular}{|c|c|c|c|c|}
\hline $\mathrm{n}$ & Map ID & Map name & Number of protein & $P$ value \\
\hline 1 & map04672 & Intestinal immune network for IgA production & 5 & $7.81 E-05$ \\
\hline 2 & map05321 & Inflammatory bowel disease (IBD) & 5 & 0.000244 \\
\hline 3 & map05140 & Leishmaniasis & 7 & 0.001049 \\
\hline 4 & map04670 & Leukocyte transendothelial migration & 11 & 0.001234 \\
\hline 5 & map04510 & Focal adhesion & 14 & 0.001851 \\
\hline 6 & map05310 & Asthma & 4 & 0.003388 \\
\hline 7 & map05164 & Influenza A & 10 & 0.004899 \\
\hline 8 & map05144 & Malaria & 5 & 0.005231 \\
\hline 9 & map04514 & Cell adhesion molecules (CAMs) & 8 & 0.007151 \\
\hline 10 & map05145 & Toxoplasmosis & 8 & 0.007151 \\
\hline 11 & map00982 & Drug metabolism-cytochrome P450 & 6 & 0.007464 \\
\hline 12 & map04973 & Carbohydrate digestion and absorption & 4 & 0.009718 \\
\hline 13 & map04972 & Pancreatic secretion & 7 & 0.010504 \\
\hline 14 & map05143 & African trypanosomiasis & 5 & 0.010539 \\
\hline 15 & map04530 & Tight junction & 9 & 0.013667 \\
\hline 16 & map04975 & Fat digestion and absorption & 4 & 0.014458 \\
\hline 17 & map04960 & Aldosterone-regulated sodium reabsorption & 4 & 0.014458 \\
\hline 18 & map05204 & Chemical carcinogenesis & 6 & 0.015534 \\
\hline 19 & map04974 & Protein digestion and absorption & 6 & 0.01907 \\
\hline 20 & map05150 & Staphylococcus aureus infection & 6 & 0.01907 \\
\hline 21 & map00983 & Drug metabolism-other enzymes & 4 & 0.020278 \\
\hline 22 & map05332 & Graft-versus-host disease & 4 & 0.020278 \\
\hline 23 & map04978 & Mineral absorption & 4 & 0.020278 \\
\hline 24 & map04933 & AGE-RAGE signaling pathway in diabetic complications & 6 & 0.023035 \\
\hline 25 & map05416 & Viral myocarditis & 6 & 0.023035 \\
\hline 26 & map05202 & Transcriptional misregulation in cancer & 5 & 0.023177 \\
\hline 27 & map05323 & Rheumatoid arthritis & 5 & 0.023177 \\
\hline 28 & map04261 & Adrenergic signaling in cardiomyocytes & 7 & 0.02526 \\
\hline 29 & map05330 & Allograft rejection & 4 & 0.027148 \\
\hline 30 & map05320 & Autoimmune thyroid disease & 4 & 0.027148 \\
\hline 31 & map05146 & Amoebiasis & 8 & 0.029455 \\
\hline 32 & map04612 & Antigen processing and presentation & 7 & 0.033293 \\
\hline 33 & map04940 & Type I diabetes mellitus & 4 & 0.034998 \\
\hline 34 & map04666 & Fc gamma R-mediated phagocytosis & 6 & 0.03738 \\
\hline 35 & map05412 & Arrhythmogenic right ventricular cardiomyopathy (ARVC) & 5 & 0.0413 \\
\hline 36 & map04971 & Gastric acid secretion & 5 & 0.0413 \\
\hline 37 & map04640 & Hematopoietic cell lineage & 4 & 0.043728 \\
\hline 38 & map04727 & GABAergic synapse & 4 & 0.043728 \\
\hline 39 & map04145 & Phagosome & 11 & 0.043902 \\
\hline 40 & map00980 & Metabolism of xenobiotics by cytochrome P450 & 5 & 0.048381 \\
\hline 41 & map04970 & Salivary secretion & 5 & 0.048381 \\
\hline
\end{tabular}

demonstrated that the FLNA protein may interact with multiple proteins and take part in the development of tumors [16, 17]. Our iTRAQ results showed that the expression of FLNA in GC samples was decreased by 0.502 -fold compared with that in normal adjacent samples. Lv et al. [18] also showed that the expression of FLNA in GC tissues is lower than that in adjacent tissues, which is consistent with the results of our study. Their research also indicated that the survival of the FLNA low-expression group was significantly lower than that of the FLNA high-expression group. Zhai et al. [19] observed that the proliferation, invasion, and metastasis ability of hepatocellular carcinoma, colorectal cancer cells, and nasopharyngeal carcinoma cells were significantly reduced when FLNA was highly expressed. 


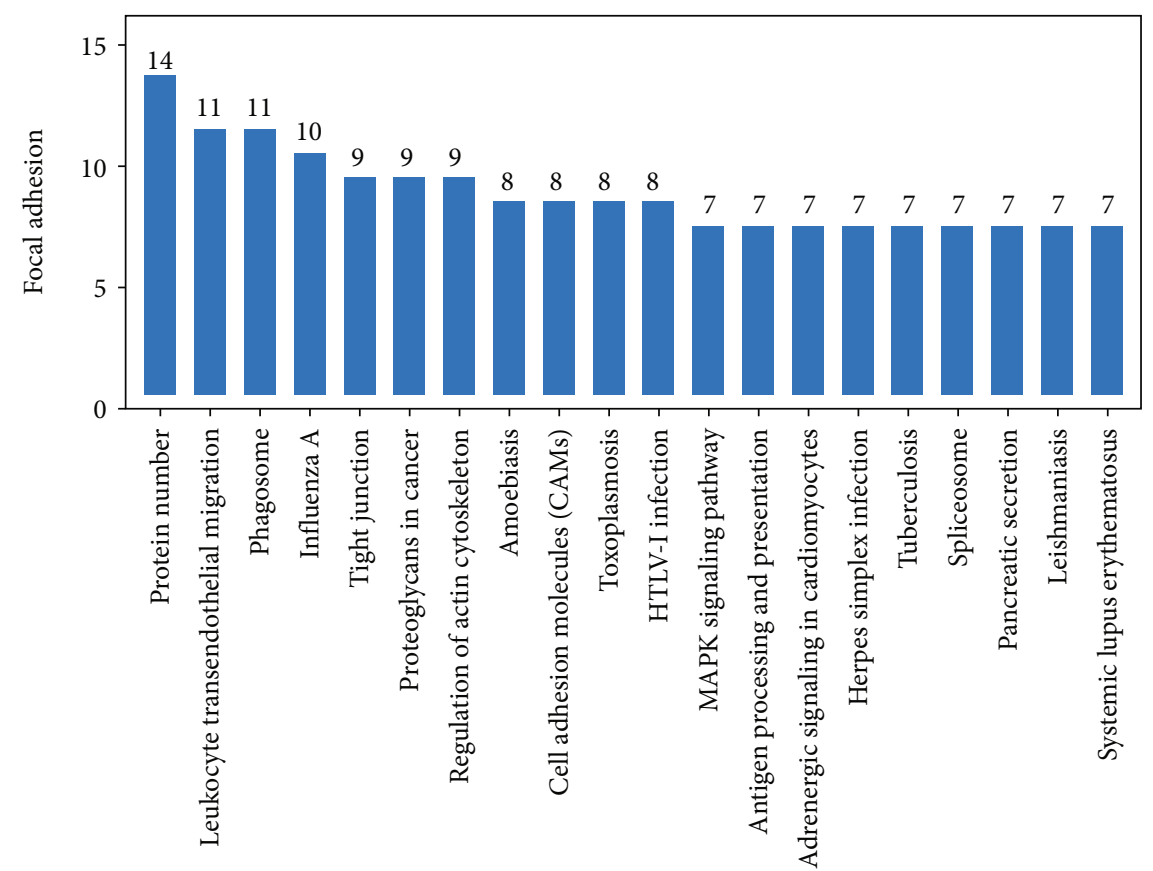

KEGG pathways (top 20)

(a)

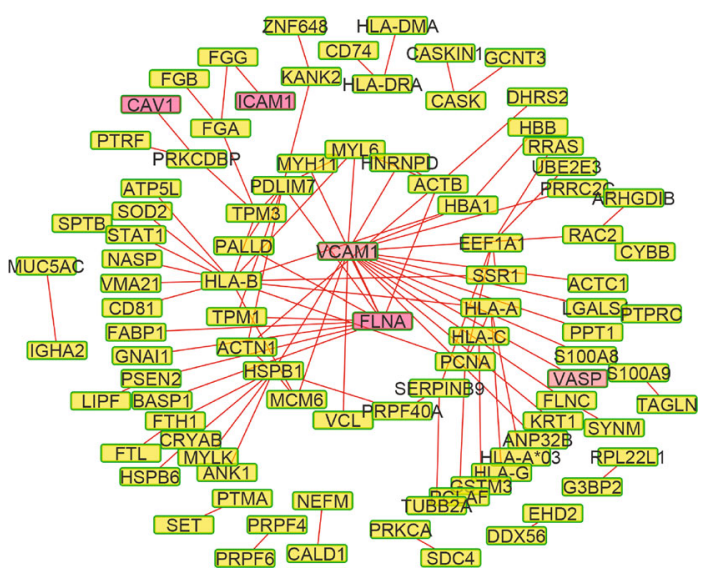

(b)

FIgURE 3: KEGG pathway and PPI analysis of the differentially expressed proteins. (a) The top 20 KEGG pathways with differentially expressed protein enrichment. (b) VCAM1 was located at the center of the PPI network.

Zhao et al. [20] indicated that xenografted mice with FLNA knockdown showed an enhanced response to docetaxel compared with control xenografted mice with increased apoptosis. Topoisomerase II (TOPO II A) is located in the nucleus of human cells and is a critical enzyme involved in biological behavior, such as DNA replication, transcription, translation, repair, and recombination, chromosome segregation, and nucleic acid conformation [21]. Reports have indicated that the expression of TOPO II A is related to tumor growth and stage, the invasion of tumor cells into the surrounding tissue, and the metastasis of the tumor. Uesaka et al. [22] demonstrated that patients with high expression of TOPO II mRNA are more sensitive to etoposide. Lu et al. [23] showed that the gene is a crucial mediator of apoptosis triggered by doxorubicin. FILIP1L levels were increased markedly through transcriptional mechanisms following treatment with doxorubicin and other TOP2 inhibitors, including etoposide and mitoxantrone, but not the TOP2 catalytic inhibitors merbarone or dexrazoxane. These results indicate that the FILIP1L expression status in tumors may influence the response to anti-TOP2 chemotherapeutics. These studies imply that FLNA might participate in drug resistance to chemotherapy via its enhanced antiapoptosis ability.

Vasodilator-stimulated phosphoprotein (VASP) plays an important role in the three-dimensional structure of actin protein and participates in the process of cell migration. VASP is involved in tumor invasion and/or metastasis 
TABLE 4: The 14 differentially expressed proteins enriched in "focal adhesion" pathway.

\begin{tabular}{lccccc}
\hline $\mathrm{n}$ & Accession & GN & Description & $P$ value \\
\hline 1 & P12111 & COL6A3 & CO6A3_HUMANCollagen alpha-3 (VI) chain OS=Homo sapiens GN=COL6A3 PE=1 SV=5 & 0.0196709 \\
2 & Q15746 & MYLK & MYLK_HUMANMyosin light chain smooth muscle OS=Homo sapiens GN=MYLK PE=1 SV=4 & $2.14273 E-05$ \\
3 & K7EM16 & VASP & VASP_HUMANVasodilator-stimulated phospho OS=Homo sapiens GN=VASP PE=1 SV=3 & 0.000027793 \\
4 & Q14315 & FLNC & FLNC_HUMANFilamin-C OS=Homo sapiens GN=FLNC PE=1 SV=3 & 0.000039772 \\
5 & P21333 & FLNA & FLNA_HUMANFilamin-A OS=Homo sapiens GN=FLNA PE=1 SV=4 & 0.000120726 \\
6 & B7Z2N5 & ACTN2 & ACTN2_HUMANAlpha-actinin-2 OS=Homo sapiens GN=ACTN2 PE=1 SV=1 & 0.000524345 \\
7 & B7Z952 & PARVA & PARVA_HUMANAlpha-parvin OS=Homo sapiens GN=PARVA PE=1 SV=1 & 0.00113605 \\
8 & P12814 & ACTN1 & ACTN1_HUMANAlpha-actinin-1 OS=Homo sapiens GN=ACTN1 PE=1 SV=2 & 0.00271591 \\
9 & A8K6A5 & ITGA5 & ITA5_HUMANIntegrin alpha-5 OS=Homo sapiens GN=ITGA5 PE=1 SV=2 & 0.0030417 \\
10 & Q03135 & CAV1 & CAV1_HUMANCaveolin-1 OS=Homo sapiens GN=CAV1 PE=1 SV=4 & 0.0047552 \\
11 & A0A024QZN4 & VCL & VINC_HUMANVinculin OS=Homo sapiens GN=VCL PE=1 SV=4 & 0.0063742 \\
12 & A0A169TED2 & PRKCA & KPCA_HUMAN kinase C alpha type OS=Homo sapiens GN=PRKCA PE=1 SV=4 & 0.0136269 \\
13 & P08572 & COL4A2 & CO4A2_HUMANCollagen alpha-2 (IV) chain OS=Homo sapiens GN=COL4A2 PE=1 SV=4 & 0.0140035 \\
14 & B4DTY8 & ITGA1 & ITA1_HUMANIntegrin alpha-1 OS=Homo sapiens GN=ITGA1 PE=1 SV=2 & 0.029126 \\
\hline
\end{tabular}

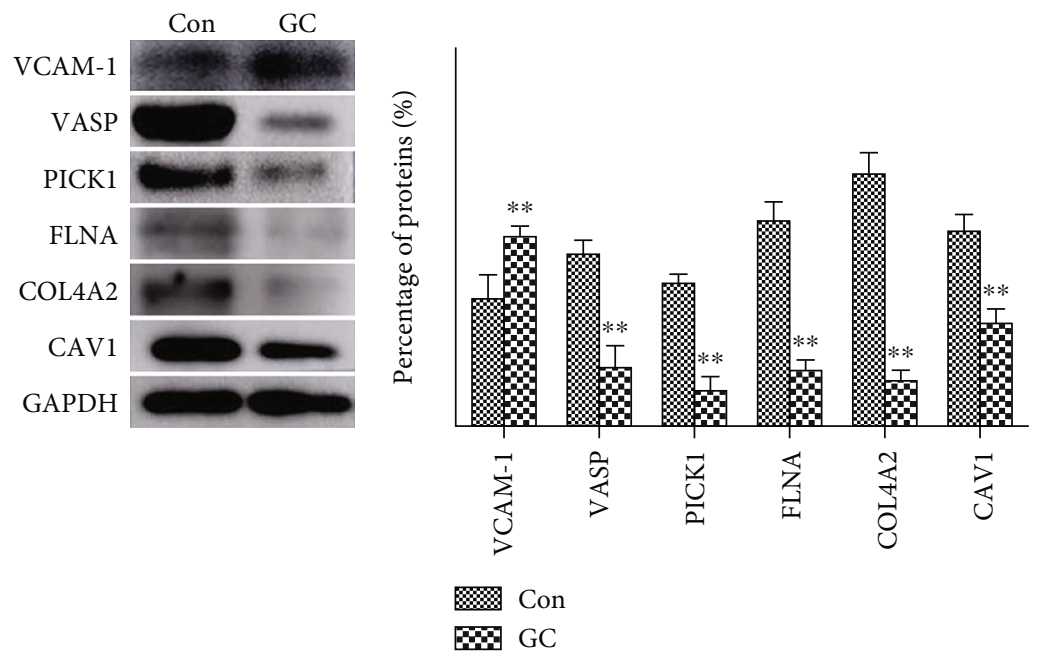

FIGURE 4: Western blotting was performed to measure the levels of VCAM1, FLNA, VASP, CAV1, PICK1, and COL4A2 in GC and adjacent normal tissues. ${ }^{* *} P<0.01$.

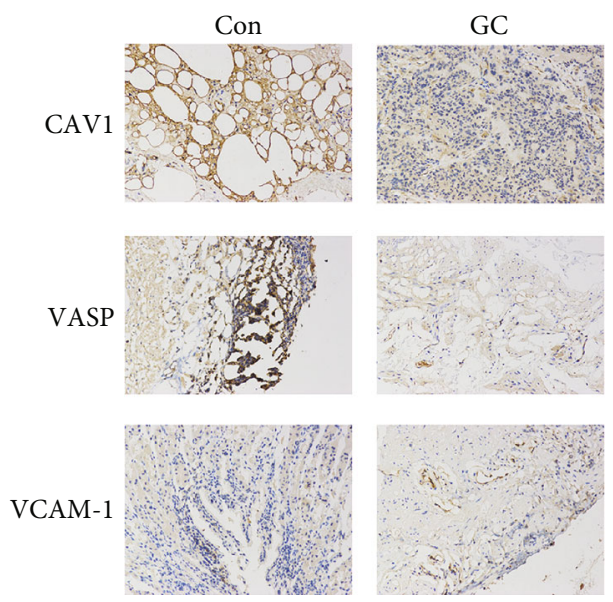

FIGURE 5: The expression levels of CAV1, VASP, and VCAM1 in GC and adjacent normal tissues were verified by IHC assays. ${ }^{* * *} P<0.001$. 


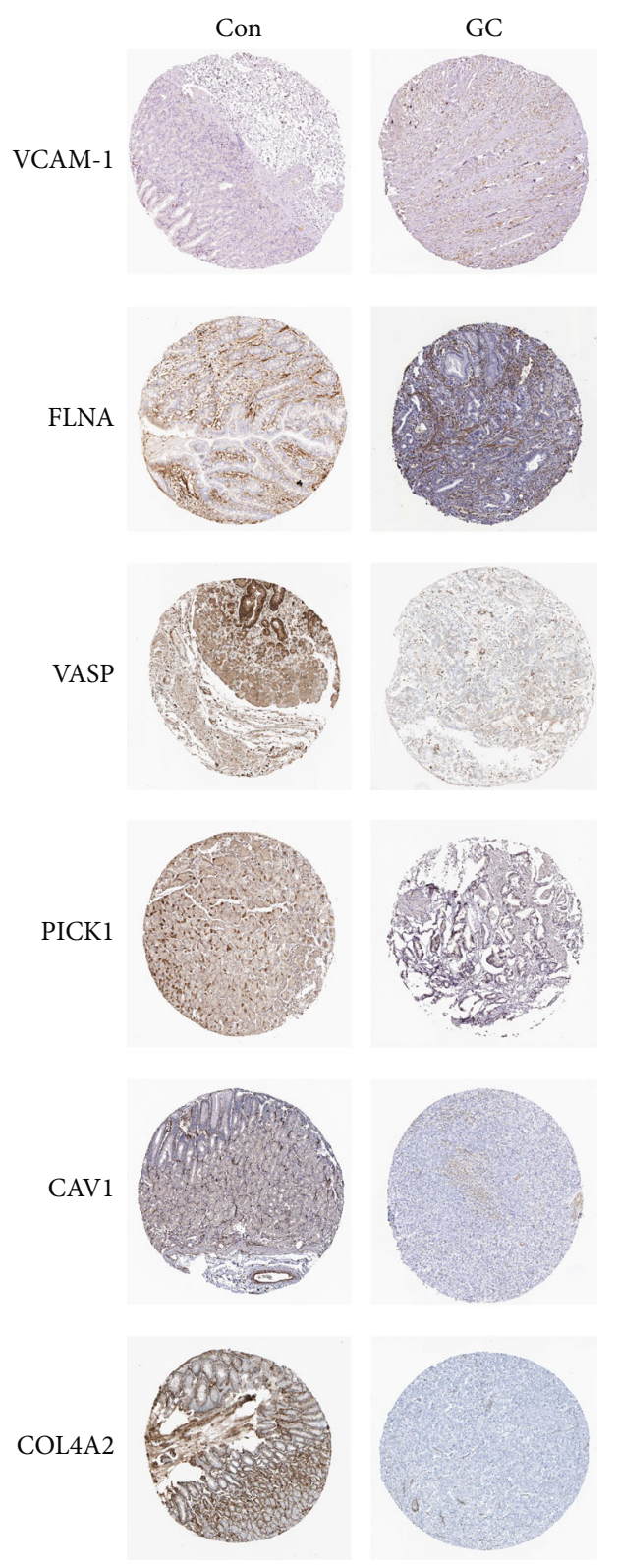

Figure 6: The protein levels of VCAM1, FLNA, VASP, CAV1, PICK1, and COL4A2 in GC and adjacent normal tissue. Images were obtained from the Human Protein Atlas (http://www.proteinatlas.org/).

progression [24]. COL4A2 is involved in tight junctions between a variety of human cells and plays a role in the adhesion of cancer cells [25]. Our results showed that the expression of VASP and COL4A2 in GC tissue was decreased compared with that in normal adjacent tissues. We speculate that the decreased expression of VASP reduced the adhesion and aggregation of tumor cells, which may lead to the invasion and metastasis of tumor cells into their surroundings. In addition, the expression of CAV1 (caveolin 1) and VCAM-1 (vascular cell adhesion molecule-1) in GC tissue was also consistent with that described in previous reports $[26,27]$. However, the expression of PICK1 (protein kinase C alpha) was upregulated in our research, which is entirely different from the results of Sun et al.'s research [28]. This

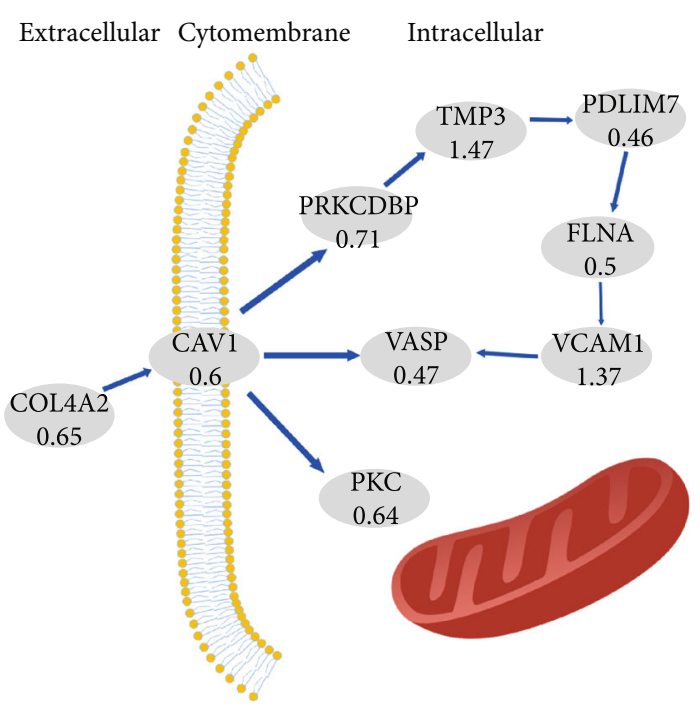

Figure 7: A simple activity flowchart of the main differentially expressed proteins.

might be because the expression of PICK1 is related to the stage of GC, and the mixed samples used in our research were different from the samples they used, which led to different results.

In conclusion, we investigated the differential protein expression in gastric cancer tissues and normal gastric mucosa using iTRAQ technology to explore the mechanism involved in gastric cancer. Six highly differentially expressed proteins were screened to identify the potential intersections between the differentially expressed proteins and abnormally expressed genes. This exploratory research may provide useful information for the clinical treatment of GC.

\section{Data Availability}

No data were used to support this study.

\section{Conflicts of Interest}

The authors declare that there are no conflicts of interest.

\section{Authors' Contributions}

The first author is Zhihua Gao.

\section{Acknowledgments}

We appreciate the work of our colleagues in 5 clinical departments (the first insurance outpatient ward, tumor surgical ward, gastrointestinal breast surgical ward, Department of Pathology, and Department of Gastroenterology), the Armed Police Logistics College, the central laboratory, and the Rescue Research Institute. We also acknowledge the guidance and help of the Institute of Shanghai. In addition, we thank the patients and their families for understanding and supporting our research work, and we acknowledge the hard work of each member of this team. This study 
was supported by the National Natural Science Foundation of China (81273745), the Tianjin Science Foundation (11JCYBJC10900), the Sub Project of the Key Projects of Tianjin (grant no. 15ZXLCSY00040-08), and the Science and Technology Program of Tianjin, China (grant no. 16ZXHLSY00120).

\section{References}

[1] Chinese Society of Digestive Endoscopy, "Consensus on the screening, endoscopic diagnosis and treatment of early gastric cancer in China (Changsha)," Chinese Journal of Digestion, vol. 19, no. 7, pp. 408-427, 2014.

[2] L. Zheng, C. Wu, P. Xi et al., "The survival and the long-term trends of patients with gastric cancer in Shanghai, China," BMC Cancer, vol. 14, no. 1, p. 300, 2014.

[3] D. Liu, M. Lu, J. Li et al., "The patterns and timing of recurrence after curative resection for gastric cancer in China," World Journal of Surgical Oncology, vol. 14, no. 1, p. 305, 2016.

[4] T. Wang, H. Cai, S. Sasazuki et al., "Fruit and vegetable consumption, Helicobacter pylori antibodies, and gastric cancer risk: a pooled analysis of prospective studies in China, Japan, and Korea," International Journal of Cancer, vol. 140, no. 3, pp. 591-599, 2017.

[5] Y. Lin, J. Ueda, S. Kikuchi et al., "Comparative epidemiology of gastric cancer between Japan and China," World Journal of Gastroenterology, vol. 17, no. 39, pp. 4421-4428, 2011.

[6] K. O. Alfarouk, C. M. Stock, S. Taylor et al., "Resistance to cancer chemotherapy: failure in drug response from ADME to P-gp," Cancer Cell International, vol. 15, no. 1, p. 71, 2015.

[7] C. Yu, M. Zhou, X. Zhang, W. Wei, X. Chen, and X. Zhang, "Smart doxorubicin nanoparticles with high drug payload for enhanced chemotherapy against drug resistance and cancer diagnosis," Nanoscale, vol. 7, no. 13, pp. 5683-5690, 2015.

[8] N. D. Amoedo, E. Obre, and R. Rossignol, "Drug discovery strategies in the field of tumor energy metabolism: limitations by metabolic flexibility and metabolic resistance to chemotherapy," Biochimica et Biophysica Acta, vol. 1858, no. 8, pp. 674685, 2017.

[9] P. Yu, Y. du, L. Yang, S. Fan, J. Wu, and S. Zheng, "Significance of multidrug resistance gene-related proteins in the postoperative chemotherapy of gastric cancer," International Journal of Clinical and Experimental Pathology, vol. 7, no. 11, pp. 7945-7950, 2014.

[10] K. G. Calderón-González, M. L. V. Rustarazo, M. L. LabraBarrios et al., "Determination of the protein expression profiles of breast cancer cell lines by quantitative proteomics using iTRAQ labelling and tandem mass spectrometry," Journal of Proteomics, vol. 124, pp. 50-78, 2015.

[11] Y. Ma, T. Xiao, Q. Xu, X. Shao, and H. Wang, "iTRAQ-based quantitative analysis of cancer-derived secretory proteome reveals TPM2 as a potential diagnostic biomarker of colorectal cancer," Frontiers in Medicine, vol. 10, no. 3, pp. 278-285, 2016.

[12] J. Chen, Z. Wang, X. Shen, X. Cui, and Y. Guo, "Identification of novel biomarkers and small molecule drugs in human colorectal cancer by microarray and bioinformatics analysis," Molecular Genetics \& Genomic Medicine, vol. 7, no. 7, article e00713, 2019.
[13] D. Szklarczyk, A. Franceschini, S. Wyder et al., "STRING v10: protein-protein interaction networks, integrated over the tree of life," Nucleic Acids Research, vol. 43, no. D1, pp. D447D452, 2015.

[14] W. P. Bandettini, P. Kellman, C. Mancini et al., "MultiContrast delayed enhancement (MCODE) improves detection of subendocardial myocardial infarction by late gadolinium enhancement cardiovascular magnetic resonance: a clinical validation study," Journal of Cardiovascular Magnetic Resonance, vol. 14, no. 1, p. 83, 2012.

[15] I. B. Tan, T. Ivanova, K. H. Lim et al., "Intrinsic subtypes of gastric cancer, based on gene expression pattern, predict survival and respond differently to chemotherapy," Gastroenterology, vol. 141, no. 2, pp. 476-485.e11, 2011.

[16] Z. Q. Tian, J. W. Shi, X. R. Wang, Z. Li, and G. Y. Wang, "New cancer suppressor gene for colorectal adenocarcinoma: filamin A," World Journal of Gastroenterology, vol. 21, no. 7, pp. 21992205, 2015.

[17] Y. L. Park, S. Y. Park, S. H. Lee et al., "Filamin A interacting protein 1-like expression inhibits progression in colorectal cancer," Oncotarget, vol. 7, no. 44, pp. 72229-72241, 2016.

[18] J. F. Lv and H. J. Xu, "The expression and significance of FLNA in gastric carcinoma," Medical Information, vol. 24, no. 7, pp. 2982-2983, 2011.

[19] J. Z. Hong-Fang Zhai, Q. Liu, C.-R. Yang, and G.-G. Sun, "The expression of FLNA in hepatocellular carcinoma and its effect on cell proliferation and cell invasion," Journal of Chinese Oncology, vol. 21, no. 4, pp. 304-310, 2015.

[20] P. Zhao, W. Ma, Z. Hu, L. Zang, Z. Tian, and K. Zhang, "Filamin A (FLNA) modulates chemosensitivity to docetaxel in triple-negative breast cancer through the MAPK/ERK pathway," Tumour Biology, vol. 37, no. 4, pp. 5107-5115, 2016.

[21] R. Peleg, M. Romzova, I. Kogan-Zviagin, R. N. Apte, and E. Priel, "Modification of topoisomerases in mammospheres derived from breast cancer cell line: clinical implications for combined treatments with tyrosine kinase inhibitors," $B M C$ Cancer, vol. 14, no. 1, p. 910, 2014.

[22] T. Uesaka, T. Shono, D. Kuga et al., "Enhanced expression of DNA topoisomerase II genes in human medulloblastoma and its possible association with etoposide sensitivity," Journal of Neuro-Oncology, vol. 84, no. 2, pp. 119-129, 2007.

[23] H. Lu and T. C. Hallstrom, "Sensitivity to TOP2 targeting chemotherapeutics is regulated by Oct1 and FILIP1L," PLoS One, vol. 7, no. 8, article e42921, 2012.

[24] V. Gkretsi, A. Stylianou, and T. Stylianopoulos, "Vasodilatorstimulated phosphoprotein (VASP) depletion from breast cancer MDA-MB-231 cells inhibits tumor spheroid invasion through downregulation of Migfilin, $\beta$-catenin and urokinase-plasminogen activator (uPA)," Experimental Cell Research, vol. 352, no. 2, pp. 281-292, 2017.

[25] S. R. Chen, M. Chen, X. N. Wang et al., "The Wilms tumor gene, Wt1, maintains testicular cord integrity by regulating the expression of Col4a1 and Col4a2," Biology of Reproduction, vol. 88 , no. 3 , p. $56,2013$.

[26] C. Trimmer, G. Bonuccelli, S. Katiyar et al., "Cav1 suppresses tumor growth and metastasis in a murine model of cutaneous SCC through modulation of MAPK/AP-1 activation," The American Journal of Pathology, vol. 182, no. 3, pp. 992-1004, 2013. 
[27] S. Gosk, T. Moos, C. Gottstein, and G. Bendas, "VCAM-1 directed immunoliposomes selectively target tumor vasculature in vivo," Biochimica et Biophysica Acta, vol. 1778, no. 4, pp. 854-863, 2008.

[28] Y.-C. W. Hai-Bing Sun, H.-l. Tu, N. Du, and H. Ren, "Expressions of COX-2, PKC- $\alpha$ and miR-101 in gastric cancer and their correlations," Journal of Southern Medical University, vol. 33, no. 4, pp. 559-562, 2013. 


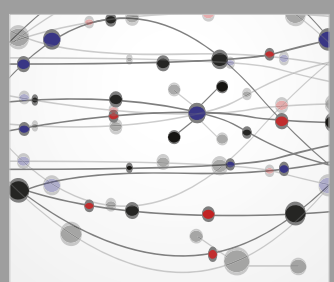

The Scientific World Journal
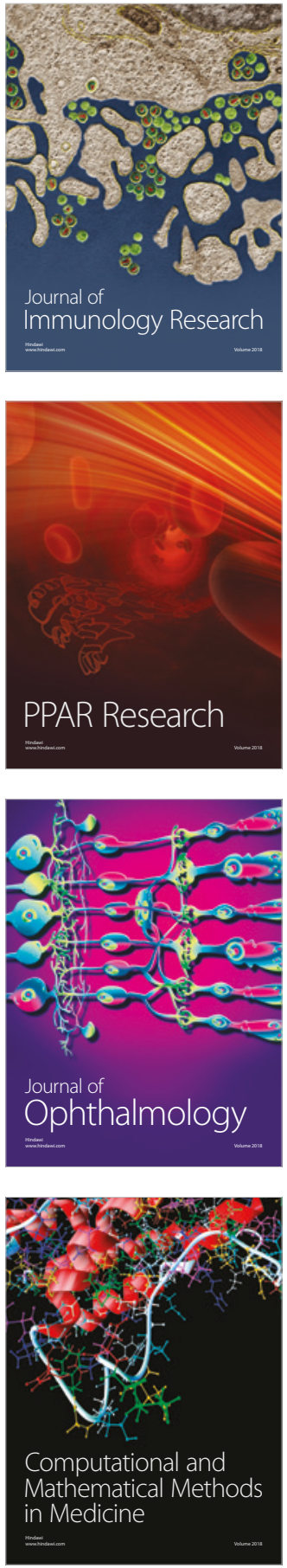

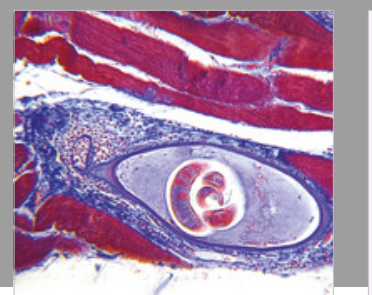

Gastroenterology Research and Practice

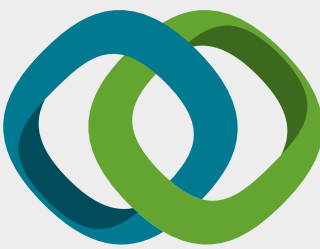

\section{Hindawi}

Submit your manuscripts at

www.hindawi.com
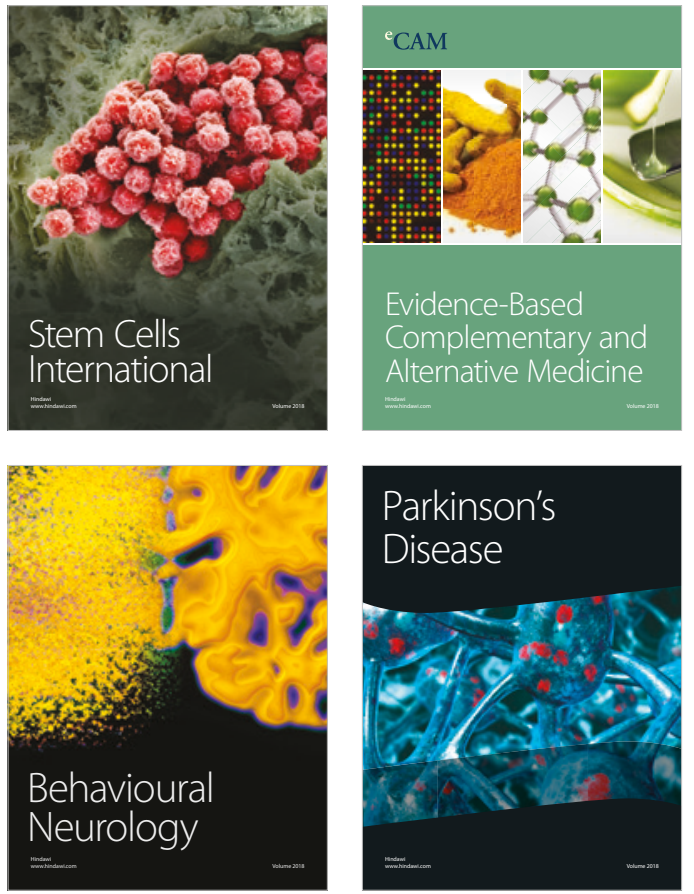

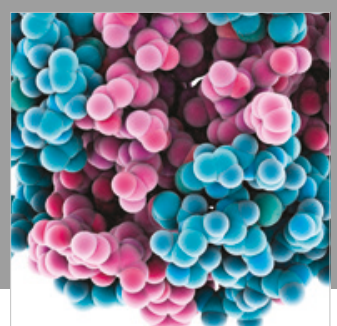

ournal of

Diabetes Research

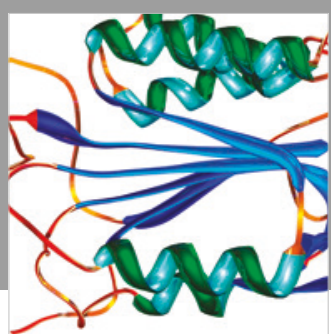

Disease Markers
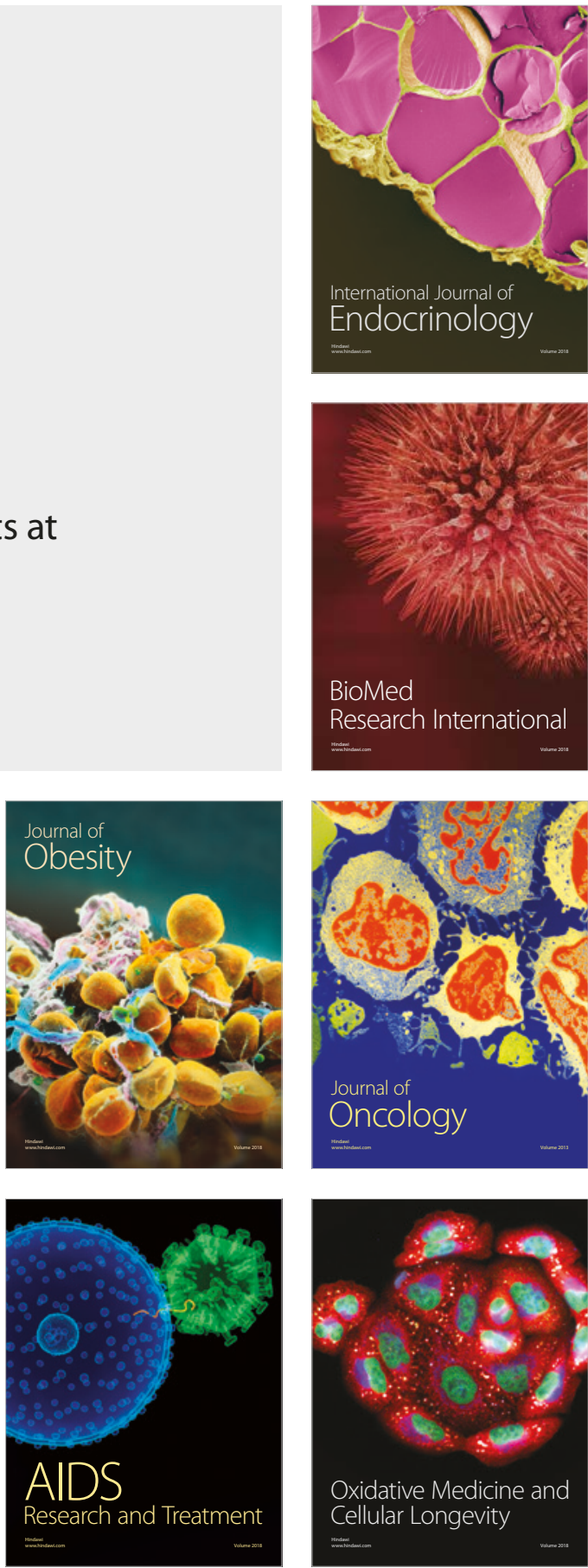